\title{
Aplasia cutis congenita
}

INSERM

\section{Source}

INSERM. (1999). Orphanet: an online rare disease and orphan drug data base. Aplasia cutis congenita. ORPHA:1114

Aplasia cutis congenita (ACC) is a rare skin disorder characterized by localized absence of skin that is usually located on the scalp but can occur anywhere on the body including the face, trunk and extremities. ACC may occasionally be associated with other anomalies. 